\title{
RESENHAS
}

REVIEWS

\section{DIREITO SANITÁRIO: SAÚDE E DIREITO, UM DIÁLOGO POSSÍVEL}

\author{
Fernando Aith, Luciana Tarbes Mattana Saturnino, Maria Gabriela Araújo \\ Diniz, Tammy Claret Monteiro, organizadores \\ Belo Horizonte, Escola de Saúde Pública de Minas Gerais, 2010
}

Thiago Marques Leão ${ }^{(*)}$

\section{INTRODUÇÃO}

Com a Constituição Federal de 1988 (CF/88), um novo modelo de proteção social emerge, fundado na cidadania e assistência universal. A consagração constitucional do direito fundamental à saúde está entre os principais avanços da $\mathrm{CF} / 88$. Esse momento de luta pela redemocratização abriu espaço para um ambiente de promoção dos direitos humanos e potencializou, dessa forma, a garantia do direito à saúde. O restabelecimento do Estado de Direito brasileiro, orientado pelo respeito aos princípios democráticos "representa a garantia primeira para que o direito à saúde seja uma realidade"(1). A constitucionalização do direito à saúde no Brasil é resultado da mobilização de grupos sociais em prol do reconhecimento de novos direitos sociais, como meio de diminuir as desigualdades sociais e restabelecer a democracia.

O direito à saúde firma-se como fundamento do Estado Democrático de Direito. A "luta pela universalização da saúde aparece como uma parte intrínseca da luta pela democracia, assim como a institucionalização da

(*) Mestrando da Faculdade de Saúde Pública, Uniuversidade de São Paulo, pesquisador do Grupo de Pesquisa Direitos Humanos, Direito à Saúde e Família, Universidade Católica de Salvador-CNPq. Salvador/BA — Brasil. E-mail: <thmleao@gmail.com>. Recebido em: 06.03.11.

(1) AITH, Fernando. Curso de direito sanitário: A proteção do direito à saúde no Brasil. São Paulo: Quartier Latin, 2007. p. 61. 
democracia aparece como condição para garantia da saúde como direito de cidadania"(2). Para efetivação desse direito, garantido mediante políticas sociais e econômicas (artigo, 196, CF/88), é necessário um constante diálogo entre a Saúde Pública e o Direito, entre os diversos atores sociais envolvidos (organizados ou não) e entre as três esferas de Poder e Governo.

Hoje, a emergência desse diálogo toma contornos cada vez mais visíveis, sob pena de inviabilizar a gestão do Sistema Único de Saúde (SUS). Questões como a chamada "judicialização da saúde" — recente alvo de discussão no Supremo Tribunal Federal — demandam pesquisa e debate. $\mathrm{O}$ livro Direito Sanitário: Saúde e Direito, um Diálogo Possível soma esforços nesse sentido. Em uma abordagem interdisciplinar, entrelaça os temas do Direito e da Saúde Pública, enfrentando questões essenciais para a manutenção do Sistema e efetivação do direito humano fundamental à saúde. O livro se organiza em quatro eixos centrais: (i) formação em direito sanitário; (ii) temas gerais de direito sanitário; (iii) consolidação do SUS; e (iv) judicialização e assistência farmacêutica. Esta resenha se propõe a apresentar, criticamente, a contribuição de cada autor, inserido nestes blocos temáticos.

O volume é organizado por Fernando Aith, Luciana Tarbes Mattana Saturnino, Maria Gabriela Araújo Diniz, Tammy Claret Monteiro, e é fruto de uma parceria entre a Escola de Saúde Pública do Estado de Minas Gerais (ESP-MG) e o Centro de Estudos e Pesquisas em Direito Sanitário (CEPEDISA), ligado ao Núcleo de Apoio à Pesquisa em Direito Sanitário da Universidade de São Paulo (NAP/DISA-USP).

\section{FORMAÇÃO EM DIREITO SANITÁRIO}

O primeiro eixo temático é composto por dois artigos, que tratam da educação continuada e formação específica em Direito Sanitário, como estratégia para qualificação do diálogo e solução de determinados embates no campo da Saúde Pública. Os artigos discutem de forma clara e consistente, a questão da formação jurídica deficiente em Direito Sanitário dos atores sociais envolvidos, e em recursos humanos em saúde, de forma mais ampliada, e suas implicações no contexto das políticas públicas e do Poder Judiciário.

No artigo Experiências de Ensino e Pesquisa em Direito Sanitário na Escola de Saúde Pública do Estado de Minas Gerais, Maria Gabriela Araújo

(2) FLEURY, Sônia. A reforma sanitária: processo histórico. In: Banco Internacional de Desenvolvimento (BID). A construção da reforma sanitária no Brasil e os desafios para os gestores. 2. ed. INDES, 2009. p. 11. 
Diniz, Tammy Angelina Mendonça Claret Monteiro e Lucimar Ladeia Colen relatam a experiência de formação de profissionais em educação sanitária, promovidas pela Secretaria Estadual de Saúde de Minas Gerais e pela ESP-MG, em parceria com o CEPEDISA/USP. Esta parceria interinstitucional busca o aprofundamento da discussão técnico-política em Direito Sanitário, agregando atores como o Ministério Público de Minas Gerais, gestores municipais da microrregião do Alto do Rio Grande, a FUNED, Conselhos de Saúde, Defensoria Pública e membros do Poder Judiciário. A ESP-MG, em parceria com o CEPEDISA/USP, organizou o I Curso de Especialização em Direito Sanitário, no período de 1998-2000, buscando a inserção de profissionais do direito e da saúde vinculados a secretarias estaduais de saúde, ao MP e ao Judiciário e "à academia".

Em seu texto, as autoras traçam o exitoso retrospectivo sobre a pós-graduação e a pesquisa em direito sanitário na ESP-MG, assim como o perfil dos alunos, cuja graduação predominante era em Direito, combinada a uma segunda na área de Saúde Pública. Este dado ganha contorno especial no atual cenário de protagonismo judicial nas políticas públicas de saúde. Uma das principais críticas ao fenômeno é o aparente despreparo dos profissionais do direito, que ignoram elementos constantes nas políticas públicas, prejudicando a gestão do Sistema ${ }^{(3)}$.

Na esteira desse debate, Thiago Campos Horta discute a formação de recursos humanos em saúde, a ausência de política específica (enquanto direito social) nesse sentido, e a importância dessa formação para efetivação dos princípios da universalização e integralidade na atenção em saúde. Em seu artigo $O$ Direito Sanitário e a Ordenação da Formação de Recursos Humanos na Saúde, Horta defende a formação de recursos humanos em saúde, no contexto mais amplo de educação continuada, aperfeiçoamento e atualização, como estratégia para promoção da saúde e concretização dos princípios constitucionais sanitários.

Em que pese as transformações e avanços nesse sentido, como a Política Nacional de Educação Permanente em Saúde do Ministério da Saúde e a experiência da SES-MG, Horta critica a ausência de políticas amplas e consistentes de formação de recursos humanos capazes de contribuir para a concretização do direito à saúde. A formação de Recursos Humanos em saúde aparece como elemento central da qualificação das práticas de saúde e, portanto, da promoção e cuidados à saúde, para enfrentamento das questões que emergem no contexto do SUS, na perspectiva da universalidade e integralidade.

(3) MARQUES, Silvia Badim; DALLARI, Sueli Gandolfi. Garantia do direito social à assistência farmacêutica no Estado de São Paulo. Revista de Saúde Pública, São Paulo, V. 41, n. 1, p. 102-107, 2007. ISSN 0034-8910. 


\section{TEMAS DA TEORIA GERAL DO DE DIREITO SANITÁRIO}

No segundo eixo temático, o livro adota uma abordagem mais ampla, para discutir os temas gerais e pressupostos do Direito à saúde - enquanto direito humano fundamental - e do Direito Sanitário. São três os capítulos que costuram esse recorte da interface entre direito e saúde. Direito Sanitário: Fundamentos, Teoria e Efetivação de Sueli Gandolfi Dallari; $A$ Saúde como Direito de Todos e Dever do Estado: o Papel dos Poderes Executivo, Legislativo e Judiciário na Efetivação do Direito à Saúde no Brasil escrito por Fernando Aith e; o texto de Sandra Regina Martini Vial intitulado O Pressuposto da Fraternidade como Condição para a Efetivação do Direito à Saúde.

Dallari, em um texto estruturado de forma muito didática, reconstrói o caminho de consolidação do direito à saúde e do Direito Sanitário, como ciência autônoma, partindo da discussão sobre direito, lei e justiça, passado pelo reconhecimento internacional do direito humano à saúde e a institucionalização dos estudos sobre Direito Sanitário nas Universidades da Europa, Estados Unidos da América e a atuação pioneira de estudiosos no Brasil, notadamente na Universidade de São Paulo. Trata do reconhecimento do direito social à saúde pela $\mathrm{CF} / 88$, bem como a previsão constitucional de mecanismos para sua efetivação, com participação popular direta (conseIhos, associações, advocacia em saúde etc.), ou por intermédio de instituições como Ministério Público, a Defensoria Pública e o Poder Judiciário.

A autora traça e decompõe as três acepções semânticas da palavra "direito" - norma (em especial a lei), permissão decorrente da norma e, qualidade do que é justo - demonstrando como, apesar do crescente distanciamento que se verifica entre a lei e a justiça (sentido comum de justiça, comungado por uma determinada comunidade em dado momento histórico), o Direito funda-se e caminha na direção da concretização do ideário de Justiça Social, não podendo deste se afastar com a pretensão de permanecer incólume. A concretização deste ideal se desloca da função legislativa, demandando amiúde atuação do Poder Executivo e da sociedade. A participação social, tanto no processo normativo como na promoção e garantia dos direitos sociais, assume papel central na concretização da democracia e da justiça social. Observou-se, sobretudo, que a formada lei afastou-se de conteúdo ético.

Dallari destaca o direito à saúde nos diplomas internacionais de direitos humanos e conceito de saúde adotado, que abrange desde o direito subjetivo à assistência médica, até a promoção de condições de vida adequadas à manutenção da dignidade humana, por parte do Estado. Em seguida, contextualiza o espaço do direito à saúde e do Direito Sanitário, no campo de conhecimento do Direito. Identifica o direito da saúde pública como parte do Direito Administrativo, pois se refere a atuações estatais orientadas pela 
própria sociedade, pelo aparelho legislativo do Estado. O direito sanitário se interessa tanto pelo direito à saúde (reivindicação de um Direito Humano), como pelo direito da saúde pública,

(...) conjunto de normas jurídicas que têm por objeto a promoção, prevenção e recuperação da saúde de todos os indivíduos que compõem o povo de determinado Estado, compreendendo, portanto, ambos os ramos tradicionais em que se convencionou dividir o direito: o público e o privado. (p. 57)

Neste artigo, destaca-se o resgate da história internacional do ensino superior em Direito Sanitário feito por Dallari, no qual ela demonstra, a partir de pesquisa realizada pela OMS, que o Direito Sanitário era ensinado, desde 1984, em praticamente todos os países da então Comunidade Econômica Europeia, sendo que na Itália e na França se encontravam os mais amplos programas de pós-graduação no tema. Assim também, nos Estados Unidos da América, a Faculdade de Saúde Pública da Columbia University oferece disciplinas afins ao Direito Sanitário. No Brasil, Dallari destaca o pioneirismo da Universidade de São Paulo que, a partir de 1987, introduziu o estudo do Direito Sanitário, como disciplina do conhecimento, com destaque para a atuação do CEPEDISA, cujas reuniões definiram a disciplina no currículo básico para o curso de especialização que, com colaborações internacionais, possibilitou a implementação regular do curso pela USP em 1989, e a institucionalização dos núcleos de apoio, com caráter interdisciplinar, abrigando especialistas de diferentes Unidades e órgãos, notadamente, o Núcleo de Pesquisa em Direito Sanitário (NAP-DISA).

Na linha de educação em saúde, para qualificação do debate e da participação popular, Dallari trata ao fim da advocacia em saúde (advocacy/ lobby - atividade de qualquer grupo de interesse visando influir na definição ou na implementação de uma política pública), destacando os meios institucionais de participação direta na Administração Pública. Esse é o caminho apontado pela autora para efetivas mudanças sociais, pela "capacitação das organizações sociais para exercerem com competência suas funções de advogados da saúde pública, e o efetivo envolvimento do Ministério Público na luta pelo respeito aos direitos assegurados na Constituição" (p. 69).

Por meio de uma reconstrução histórica dos processos de consolidação da democracia, do reconhecimento do direito à saúde como direito humano e da participação popular como âncora democrática do Estado brasileiro, Aith analisa a configuração do sistema jurídico nacional, identificando os deveres do Poder Público na efetivação do direito à saúde e o papel de cada um dos Poderes estatais e entes federativos. Ele caracteriza o direito à saúde como direito humano social, ou prestacional, isto é, que exige do Estado prestações do sentido de efetivá-lo e como direito individual, oponível ao Estado mediante ação judicial. 
Assim, o direito à saúde é ao mesmo tempo um direito social e um direito subjetivo público, individual: permite que um cidadão ou uma coletividade exijam que o Estado adote medidas específicas em benefício da sua saúde ou, ainda, que o Estado se abstenha de adotar ações que possam causar prejuízos à saúde individual ou coletiva (não poluir o ambiente, por exemplo). (p. 79).

No artigo seguinte, Aith trata da participação democrática e do constitucionalismo na modernidade, e da efetividade material dos direitos fundamentais, para além de sua dimensão meramente formal, de proteção das liberdades individuais, para a acepção de direitos fundamentais como mecanismo de combate às desigualdades sociais. Apresenta o Estado de Direito e o constitucionalismo, no contexto de promoção e garantia dos direitos humanos, seja para a limitação da atividade estatal, seja para impor ao Estado a obrigação de promover os direitos sociais por meio de prestações, como meio de combater as desigualdades sociais. Para tanto, refaz brevemente o caminho de afirmação histórica dos Direitos Humanos, com destaque para os direitos sociais. Ele parte do Estado liberal de fins do século XVIII, à afirmação constitucional dos direitos sociais, no século XX, com destaque para a constitucionalização do direito humano social à saúde, na Carta Política brasileira de 1988.

Aith discute o sentido da democracia e da democracia sanitária, nos moldes da CF/88 e da responsabilidade do Estado. Neste sentido, conclui que a promoção, proteção e recuperação da saúde dependem, sempre, da atuação direta ou indireta dos órgãos e instituições estatais, de forma harmônica, notadamente do Poder Legislativo no estabelecimento de regras gerais para atuação do Poder Público, Poder Executivo (nas 03 esferas) para execução das políticas públicas no âmbito do SUS e do Poder Judiciário na efetivação do direito à saúde no Brasil, mediante a atuação jurisdicional. Como defende Aith, a harmonia entre os Poderes é essencial para efetivação do direito à saúde, sendo imprescindível o constante diálogo entre estas instâncias e a permanente participação popular. Esta é uma "dinâmica natural do Estado de Direito, necessária ao aperfeiçoamento dos mecanismos de proteção dos direitos humanos e das ações estatais rumo a uma sociedade mais justa e fraterna" (p. 103).

Fechando este bloco de temas gerais do direito sanitário, Vial se propõe a discutir o direito à saúde a partir da metateoria de Resta sobre o Direito Fraterno, analisando a atuação de determinados "operadores do direito", como a autora os denomina. O artigo apresenta os resultados parciais da pesquisa "Construindo uma rede colaborativa para favorecer a participação popular", realizada em 2008-2009 pelo CEPEDISA, em parceria com seis centros de referência que formam a REDS (Rede de Defesa da Saúde). A pesquisa trabalha com a percepção dos atores sociais identificados, envolvidos na reivindicação do direito à saúde, pelo método do discurso do 
sujeito coletivo. O artigo tratou das entrevistas realizadas com defensores públicos e delegados de polícia, com enfoque nas questões fechadas.

Vial busca resgatar o primado da fraternidade e trabalha com a discussão levantada por Resta, tratando do Direito Fraterno que, como ela explica, funda-se na alteridade, no reconhecimento do outro como igual e, mais do que isso, do outro como irmão, com o qual se faz pactos. A ideia de pactuação é tomada como mecanismo que viabiliza o convívio fraterno e a redução das desigualdades, e como estratégia de proteção dos direitos humanos, in casu, do direito à saúde. Para tanto, a autora analisa os Pactos firmados no âmbito do SUS, com este olhar e sob a perspectiva da metateoria do Direito Fraterno.

Para quem não está familiarizado com a discussão trazida por Resta na década de 80, o capítulo parece se esquivar aos olhos do leitor. Para melhor defini-lo, Vial expõe os pressupostos do Direito Fraterno: i) identificação do outro como outro-eu, outro-irmão - o reconhecimento do outro como igual e mais, o autorreconhecimento, a identificação com outro e o que emergiria desse contexto - e a pactuação. Um acordo estabelecido entre pessoas que se identificam como iguais e, mais que isso irmãos, livremente pactuando regras de convivência; ii) não limitação geográfica e/ou política para o respeito dos direitos com universalidade, em um espaço político mais aberto e não delimitado pelo espaço do Estado-nação; iii) a humanidade e o reconhecimento das diferenças, para além dos limites do pertencimento a determinado Estado, cultura, mas com base unicamente no "ter humanidade", nas diferenças e responsabilidades compartilhadas. Quer superar a ideia geopolítica de cidadania, para uma comunidade delimitada pelo "ter humanidade"; iv) a responsabilidade e não delegação de direitos, por mecanismos próprios da sociedade, acapazes de implementar direitos que confiram autonomia aos sujeitos, como o direito à informação; v) a não violência, o que implica em jurisdição mínima, autonomia e liberdade aos sujeitos envolvidos na dinâmica e promoção e garantia do direito à saúde; vi) é um direito inclusivo, não limitado por barreiras geográficas ou políticas; e vii) fraternidade como aposta na diferença e como alternativa à lacuna petica deixada pelos primados da liberdade e da igualdade que, nas palavras da autora, não foram capazes de efetivar políticas públicas e produziram diferenciação e exclusão.

Apesar da roupagem incomum, a ideia dialoga centralmente com o conteúdo ético dos Direitos Humanos e com o princípio da dignidade humana, fundamento axiológico comum aos direitos que garantem condições indispensáveis à vida com dignidade. Em que pese a imprecisão conceitual que não chega a ser suprida, no artigo, pelos pressupostos elencados, Vial traz uma luz nova ao debate e, com certo lirismo e muita humanidade, discute o tema do direito sanitário. É um artigo ousado, que traz uma discussão que não é de fácil assimilação, notadamente quando os pressupostos de análise 
já estão por demais assentados e, por isto mesmo, pouco permeável a uma proposta com fundamentos tão diversos, daqueles comumente usados pela tradição jurídica brasileira. É uma discussão que trabalha com a edificação de paradoxos e questiona a dogmática jurídica do tempo presente ${ }^{(4)}$.

\section{CONSOLIDAÇ̃̃O DO SISTEMA ÚNICO DE SAÚDE}

O terceiro eixo temático avalia determinados debates de relevância para gestão do SUS e manutenção do Sistema. O bloco desenha um panorama abrangente e diverso sobre as questões levantadas e dialoga com os demais artigos, seja seguindo na mesma direção, ou para mostrar outras posições, cujo contraste enriquece o debate.

Em um texto muito bem estruturado e que foge à linha adotada pela maioria dos articulistas sobre o tema, Gilmar de Assis assume uma posição de defesa ao protagonismo judiciário. Em que pese suas reservas quanto à "judicialização despropositada", Assis entende que os argumentos levantados pela Administração Pública, notadamente o da reserva do possível, são inconciliáveis com as omissões políticas do Estado, que não atenderia às diretrizes e princípios constitucionais e o inadequado financiamento público em saúde. O artigo procura demonstrar os riscos de um Judiciário permeável aos discursos políticos e econômicos, em detrimento das diretrizes e dos princípios constitucionais expressamente determinados constitucionalmente, que privilegiaria os hipossuficientes, negligenciando a universalização constitucional das ações e serviços de saúde.

Assis critica a fundamentação presente na jurisprudência mineira especificamente, que usa a figura da hipossuficiência para garantir ou negar acesso a bens e serviços em saúde, ferindo princípios sanitários da universalidade e integralidade. Essas decisões, como entende o autor, são eivadas de inconstitucionalidade, indo de encontro aos princípios da legalidade e isonomia. Ele conclui que ao Poder Judiciário compete expandir seu raio de jurisdição e não acatar os discursos de natureza político-econômicos que "amenizam ou excluem a responsabilidade dos entes estatais na promoção da saúde".

Sob outra perspectiva, Luciana Guimarães Leal Sad e Rafaella Barbosa Leão delineiam, em traços gerais, a Política Nacional de Atenção Oncológica, a partir da análise crítica da legislação e jurisprudência, no que diz respeito ao fornecimento de medicamentos antineopláticos pelo SUS. Pesando os argumentos favoráveis e contrários às demandas individuais por bens e serviços de saúde, junto ao Poder Judiciário, as autoras se propõem a discutir

(4) VIAL, Sandra Regina Martini. Direito fraterno na sociedade cosmopolita. Revista do Instituto de Pesquisas e Estudos, Bauru, v. 40, n. 46, p. 119-134, jul./dez. 2006. 
a responsabilidade pelo fornecimento dos referidos medicamentos e a "controvérsia judicial acerca da legitimação passiva dos entes federados" à luz da teoria dos custos dos direitos. Com equilíbrio, elas citam Barroso e estabelecem a premissa de que "Não há solução juridicamente fácil nem moralmente simples nessa questão"(5).

Sad e Leão analisam a Política Nacional de Atenção Oncológica, sob a perspectiva legislativa (lato sensu) e jurisprudencial, buscando determinar o sistema de divisão de competências no SUS, com vista à integralidade na atenção aos usuários. Elas apresentam o leque de leituras possíveis, ao se tratar de competências e solidariedade na atenção em oncologia: (i) a competência específica, in casu, dos Centros de Alta Complexidade em Oncologia; (ii) pela competência comum entre os entes da federação; e (iii) responsabilidade solidária dos entes da Administração Pública. A crítica levantada é no sentido de que a competência comum não implica em sobreposição de ações, mas em uma atuação articulada e eficiente dos entes públicos, na garantia e promoção da saúde.

Nesse argumento, insere-se a discussão sobre a teoria dos custos dos direitos e a efetividade dos direitos sociais, que demonstra a necessidade do emprego racional e adequados dos recursos da saúde, de forma a que o direito de um não inviabilize o de tantos outros. Por isso, a importância de o judiciário atentar para as políticas públicas que buscam, em alguma medida, equacionar interesses individuais e coletivos.

Para discutir os efeitos da descentralização instituída pela CF/88, mediante da regionalização e distribuição de competências sanitárias, entre os entes da federação e seu impacto na consolidação do SUS, Kellen Pavão e Thomaz Felipe da Costa tratam do modo como os entes públicos devem atuar, singular e cooperativamente, com vistas à funcionalidade de ações e serviços em saúde. Os autores defendem que a descentralização e a regionalização funcionariam como mecanismo capaz de conferir maior efetividade ao SUS, distribuindo competências e atendendo às demandas específicas de cada região sanitária.

Pavão e Costa defendem que a descentralização e regionalização dos serviços de saúde "representam melhoria na qualidade da assistência à saúde, incluindo participação do cidadão nos processos decisórios, e permitindo que este fiscalize e avalie a prestação de serviços" (p. 190). A aproximação entre gestão pública (pelo ente público) e cidadão é fundamental para se conferir efetividade, equidade e alicerces democráticos aos serviços e ações de saúde. Neste sentido, o artigo de Pavão e Costa sinaliza para o significado da descentralização e regionalização nesse processo de implementação do SUS

(5) BARROSO, Luís Roberto. Da falta de efetividade à judicialização excessiva: direito à saúde, fornecimento gratuito de medicamentos e parâmetros para atuação judicial. Disponível em: <www.Irbarroso.com.br/pt>. Acesso em 01 mar.2011. 
e da democracia sanitária, por meio de uma rede articulada e complementar de políticas públicas para garantia do direito à saúde.

Anísia da Soledade Dias Ferreira, no artigo Regulação Estatal e Auditoria no Âmbito do Sistema Único de Saúde, segue a linha de debate sobre consolidação do SUS e discute a responsabilidade do Estado, para além de seu dever prestacional, quanto à regulação dos serviços e práticas de saúde, bem como na implementação de uma política sanitária ampla, que atenda à disposição constitucional. O artigo se comunica com o de Aith, e propõe que o Poder Público não se limite à execução de serviços em saúde, mas assuma efetivamente a macrofunção de regulador e financiador do SUS.

Ferreira destaca a importância da regulação e a fragilidade do SUS, quanto a isto, "principalmente na superintendência regulatória, que engloba vários instrumentos de gestão como a certificação dos serviços de saúde, a avaliação tecnológica em saúde e o controle e avaliação dos sistemas e serviços de saúde" (p. 208). Delineada esta lacuna e fragilidade, o autor pontua a necessidade de avançar na discussão sobre o papel do Estado e da necessária constituição de bases para organização da atividade de controle, avaliação e auditoria dos serviços de saúde.

Encerrando este bloco temático, o artigo Participação Social na Agência Nacional de Vigilância Sanitária, de Rachelle A. A. Balbinot e Lucas Hernandes Corrêa, discute a institucionalização da participação social na saúde e seus mecanismos de efetivação, no contexto da Agência de Vigilância Sanitária (ANVISA). Para tanto, revisitam a história recente da proteção à saúde no Brasil, e a VIII Conferência de Saúde de 1986, onde os valores do Movimento de Reforma Sanitária voltaram à pauta, com o fim do período da ditadura militar, e posteriormente foram incorporados à Carta Constitucional de 1988.

Em 1999, a ANVISA foi instituída por meio da Lei n. 9.782, com o objetivo de coordenar e normatizar o Sistema de Vigilância Sanitária, exercendo atividades de regulação, controle e fiscalização em vigilância sanitária. A autarquia é permeável à participação popular e tem mecanismos institucionalizados à disposição do cidadão. Balbinot e Corrêa tratam da participação social em saúde, como forma de controle que a sociedade exerce sobre o Estado e instrumento para implementação efetiva da democracia. Em particular, a participação nas agências reguladoras estimula a competição e proteger os interesses da população. Segundo os autores, as agências devem ser vistas pela população como

(...) um lugar privilegiado para receber informações, esclarecer dúvidas, denunciar, isto é, o local onde possa encontrar uma possibilidade de que sua voz seja ouvida e seu direito protegido, afinal esta é (ou deveria ser) a grande atribuição da agência, porque, entre os objetivos de sua criação, está a permeabilidade à participação da população. Resta saber se a institucionalização garante a realização. (p. 249) 
Balbinot e Corrêa elencam os mecanismos institucionais de participação social e sua abrangência, citando as audiências públicas, câmaras setoriais, câmaras técnicas, o conselho consultivo, as consultas públicas e a ouvidoria. Seguindo uma das linhas que dá unidade e contorno especial a esta publicação, os autores tratam de forma privilegiada a participação social — aqui no contexto da ANVISA - como instrumento de consolidação da democracia e do SUS, e proteção à saúde.

\section{JUDICIALIZAÇÃO DA SAÚDE E ASSISTÊNCIA FARMACÊUTICA}

O último eixo do livro aborda uma das questões de talvez maior efervescência no debate acadêmico atualmente: o fenômeno da chamada judicialização das políticas públicas de saúde, com destaque para as demandas por medicamentos. Com a crescente busca pela tutela jurisdicional do direito à saúde, os atores sociais têm-se visto obrigados a lidar com o tema ${ }^{(6)}$. Nesse ponto, o livro tem o mérito de apresentar um panorama do fenômeno em Minas Gerais, fornecendo elementos importantes para se construir um quadro abrangente e detalhado sobre a questão, em termos nacionais, o que possibilita a busca de respostas eficazes para questão.

Tomando como ponto de partida a assistência farmacêutica da Secretária Estadual de Saúde de Minas Gerais, Daniel Resende Faleiros, Luciana Tarbes Mattana Saturnino, Eli lola Gurgel Andrade, Ana Luisa Caires de Souza, Antônio Jorge de Souza Marques e Augusto Afonso Guerra Junior discutem o fenômeno da judicialização, a incorporação de novas tecnologias por força de decisões judiciais e os riscos inerentes a isso. Em que pese os benefícios potenciais que a judicialização poderia trazer para efetivação do direito à saúde, os riscos à gestão causados por essas decisões são inúmeros.

Faleiros et al. relatam o imenso impacto orçamentário causado pela aquisição desordenada, a sobrecarga de recursos humanos empregados para atender a estas demandas e o retorno de usuários graças ao uso não racional dos medicamentos requeridos judicialmente. Por conta disso, a SES-MG tem buscado atuar de forma qualificada, com vistas à garantia efetiva do direito à assistência terapêutica integral, com segurança, eficácia e custo efetivo favorável, com base em evidências científicas. $O$ artigo demonstra os riscos tanto à gestão e à saúde coletiva, como à saúde individual, do uso irracional de medicamento e a incorporação desregrada de novas tecnologias, sem o devido cuidado.

Fernanda Pereira Zhouri, Flávia Naves Vilela Oliveira, Kammilla Éric Guerra de Araújo, Keyla Tatiana Rosa Pereira e Marilene Barros de Melo

(6) MARQUES, Silvia Badim. Judicialização do direito à saúde. Revista de Direito Sanitário, São Paulo, v. 9, n. 2, p. 65-72, out 2008, ISSN 1516-4179. 
apresentam o perfil das decisões judiciais do Tribunal de Justiça do Estado de Minas Gerais (TJMG) e discutem os fundamentos processuais dessas decisões. O artigo é resultado dos trabalhos da Pesquisa "Saúde no Tribunal: Jurisprudência e Políticas Públicas em Confronto", cujo objetivo é "investigar e compreender as decisões emanadas pelo Poder Judiciário no que tange aos pedidos de serviços de saúde em face dos entes competentes e suas implicações no processo de gestão do SUS bem como, analisar as políticas públicas de saúde" (p. 297).

A pesquisa identifica elenca as principais questões presentes nestas decisões e a posição do Tribunal quanto a elas, de forma a traçar um perfil dessas decisões, que demonstra um descompasso entre a atuação do Judiciário e as políticas públicas. Neste sentido, Zhouri et al. defendem o diálogo e a interação entre diversos sujeitos envolvidos no fenômeno da judicialização de modo que se possa promover ações efetivas para garantia da saúde do cidadão, com condições de vida dignas.

Na sequência, compondo este quadro sobre a judicialização no Estado de Minas Gerais, Leandro Rodrigues Machado, Ana Luísa Rivelli de Resende e Luciana Tarbes Mattana Saturnino analisam o perfil das demandas por medicamentos, junto ao Poder Judiciário mineiro. Em pesquisa na página eletrônica do Tribunal de Justiça de Minas Gerais, buscando decisões de $2^{a}$ instância e identificando pedidos por medicamentos no período de janeiro a abril de 2008, foram identificados 357 acórdãos, tratando de 667 pedidos, uma vez que muitas demandas diziam respeito a mais de um medicamento.

Machado, Rivelli e Saturnino identificaram dentre outras, informações sobre o polo passivo, classe da ação e decisão, sobre o medicamento solicitado e suas características, inclusive se eram padronizados e, em caso positivo, a qual programa pertenciam e preços dos medicamentos demandado e pago pelo SUS. Os autores concluíram que os dados encontrados são condizentes com o que vem sendo pesquisado no restante do país. As decisões apesar de fundamentadas no direito à saúde e nos dispositivos constitucionais atinentes, não abrangem as normas condições e normas específicas de medicamentos, que são estratégicas para garantir a gestão saudável e racional do SUS e, assim, garantir a efetividade do direito à saúde.

Na mesma linha do artigo anterior, Priscila Satler de Paula e Luciana Tarbes Mattana Saturnino, com maior especificidade, descrevem as demandas pelo medicamento etanercepte, no Estado de Minas Gerais, no período de janeiro a abril de 2008. A pesquisa encontrou 159 processos demandando um medicamento especializado e destes, 35 tinham por objeto o medicamento Enbrel ou Etanercepte. Satler e Saturnino identificaram que a via judicial foi utilizada como meio de acesso e garantia à assistência farmacêutica, pontuando a necessidade de se reavaliar as evidências científicas e o custo-efetividade para uma possível atualização do protocolo. 
As autoras sinalizam ainda para a importância da sistematização dos dados para monitoramento das demandas judiciais, como via de avaliar os serviços de saúde relativos às demandas.

No quinto artigo deste bloco (Capítulo XV), Avaliação do Uso de Medicamentos não Registrados no Brasil Demandados por Meio de Ações Judiciais no Estado de Minhas Gerais, escrito por Priscila Oliveira Fagundes e Ricardo Chiappa, há análise das ações judiciais por medicamentos sem registro na ANVISA, em face do Estado de Minas Gerais. A relação de medicamentos foi adquirida junto à SES-MG, do rol de medicamentos importados adquiridos, no período de 1ํ de janeiro de 2009 a maio de 2010, por imposição judicial. De acordo com Fagundes e Chiappa,

os riscos e danos à saúde relacionados com o consumo de produtos, tecnologias e serviços de interesse sanitário podem ser decorrentes de diversas variáveis, desde as poucas evidências científicas de eficácia do produto até o uso indiscriminado e inadequado desses. (p. 354/355)

Para prevenir, reduzir e eliminar estes riscos e agravos à saúde da população, e buscando garantir que os medicamentos comercializados em território nacional sejam de qualidade, seguros e eficazes, a ANVISA tem, entre outros atributos, a responsabilidade para autorizar e registrar de novos produtos, incluídos aí os medicamentos. A pesquisa identificou 30 medicamentos importados nos moldes propostos, sendo que 14 deles (12 fármacos distintos) não possuíam registro junto à ANVISA. Fagundes e Chiappa argumentam, porém que estas demandas não têm ganhado força no Estado de Minas Gerais, não correspondendo a uma prática comum e, apesar do maior cuidado por parte do Poder Judiciário, com demandas desta natureza, ainda é preciso que gestores e judiciário unam forças na garantia do direito à assistência farmacêutica de qualidade, segura e eficaz.

No mesmo sentido, é o estudo de Henrique Maciel dos Santos Moreira, Itália Viviani de Lacerda Capanema e Vânia Faerman Rabello, que analisa o uso de medicamentos e tratamentos experimentais por força de decisões judiciais, e os riscos dessa prática para a saúde do cidadão. O tratamento experimental consiste no tratamento ou medicamento que, sem prévio registro e autorização da ANVISA, é utilizado em território nacional. Moreira, Capanema e Rabello explicam que os medicamentos para serem autorizados e registrados na ANVISA passam por uma série de testes clínicos. Aqueles não aprovados nas três primeiras fases de teste não podem ser comercializados no país, e sua utilização está restrita às pessoas que assinaram o Termo de Consentimento Livre e Esclarecido.

O estudo destaca, ainda, decisões recentes do Tribunal de Justiça do Rio Grande do Sul (TJRS), que vem tomando suas decisões com cautela e de forma a tomar uma decisão fundamentada. Assim, "diversas questões são sopesadas antes de se deferir o pedido relativo ao tratamento experimental, 
tais como os critérios técnicos que levaram o sistema de saúde pública do país a disponibilizar um tratamento de tal forma, ou mesmo não disponibilizá-lo à população" (p. 407). Moreira, Capanema e Rabello analisam a mesma questão, a partir das decisões dos Tribunais Superiores e as implicações dessas decisões e do tratamento experimental, para as políticas públicas de saúde.

Fernando Aith, Flávia Naves Vilela Oliveira, Jamara Alves e Keyla Tatiana Rosa Pereira resgatam a evolução do entendimento sobre a efetivação do direito à saúde, por parte do Poder Judiciário Mineiro. O artigo toma como base de análise os dados do sistema de armazenamento de decisões judiciais da ESP-MG, no período de 2000 a 2007. Os dados coletados demonstram um crescimento consistente das demandas por medicamentos no Estado de Minas Gerais. Em contrapartida, as decisões favoráveis ao Estado, que se mantinham estáveis, em 2006 aumentaram em número. Assim também, as decisões contrárias ao Estado mantiveram-se estáveis.

Este dado é particularmente interessante, pois mostra, como ressaltam Aith et al, "uma discreta mudança de posicionamento dos julgadores ao analisar as ações de saúde em questão" (p. 377). Além desses dados, os autores analisaram a natureza dos pedidos, o número de ações ajuizadas pelo Ministério Público em relação às demandas individuais $(73,7 \%$ do total de ações interpostas pelo Parquet), o polo passivo das demandas com prevalência do Município, o crescimento por tipo de ação em especial do Mandado de Segurança, de 2004 a 2007, o arcabouço probatório que instruiu estes pedidos e o deferimento de pedidos em sede liminar. Neste último quesito, os números são expressivos: em $84 \%$ dos acórdãos estudados, as demandas tiveram seus pedidos liminares atendidos.

Os resultados apresentados por Aith et al coincidem com aqueles apresentados por Rita de Cássia Costa da Silva, que no seu artigo analisa a evolução das ações judiciais na microrregião de Saúde de Betim, em Minas Gerais, no período de 2000 a 2008. Dentre as ações estudadas, $73 \%$ obtiveram a antecipação dos efeitos da tutela. Em 54,85\% das ações intentadas pelo Ministério Público, as demandas eram de natureza individual e das 26 ações, 22 tinham o Município figurando no polo passivo. Silva, comungando com os demais autores deste eixo, aponta para as implicações destas decisões sobre as políticas públicas de saúde, evidenciando o necessário diálogo e articulação entre gestores e "operadores do direito" (p. 395).

Os dados coincidentes nas pesquisas de Aith et al e Silva demonstram a coerência do trabalho feito e a potencialidade do estudo, como instrumento para desvendar e dar respostas concretas às questões levantadas pelo protagonismo judicial.

Na última contribuição deste volume, para caracterizar o fenômeno da judicialização no Estado de Minas Gerais, Cristiane de Oliveira Elian 
apresenta o artigo Efeitos da Coisa Julgada nas Ações Coletivas e o Caso da Hepatite $C$. Neste trabalho, a autora parte de um caso concreto, o julgamento da Ação Civil Pública n. 024.03.031.752-3, quando o Estado de Minas Gerais foi condenado a fornecer o medicamento Interferon Peguilado a "todos os pacientes do SUS, portadores de Hepatite C, presentes e futuros, na quantidade indicada pelo médico e enquanto durar a prescrição".

Elian discute, neste contexto, se a Administração Pública, em virtude da decisão judicial transitada em julgado, deve deixar de aplicar os critérios de inclusão e exclusão, estabelecidos no Protocolo Clínico e para a Hepatite C do Ministério da Saúde (Portaria SAS/MS n. 34/07), que após o trânsito em julgado da referida decisão, revogou a Portaria SAS/MS n. 863/02, que até então regulava o acesso ao programa de atenção à doença.

Para tanto, a autora aborda a questão da Hepatite C e o Programa Público de Saúde existente no cenário nacional e em Minas Gerais; os protocolos clínicos como mecanismos de elaboração das políticas públicas em saúde; a ação civil pública e o controle judicial das políticas públicas de saúde; e o efeito erga omnes nas ações coletivas e a relativização da coisa julgada.

O artigo escrito com muita clareza, a despeito da profundidade com que trata das questões propostas, é muito interessante pela amplitude da questão e pela peculiaridade do caso concreto estudado. O estudo conclui, entre outras coisas, que o uso não racional de medicamentos e tecnologias pode obstaculizar a implementação das políticas públicas e, assim, a garantia do direito à saúde; urge que se reconheça a relevância dos protocolos e diretrizes clínicas para manutenção da estrutura do SUS, pela participação efetiva da sociedade na elaboração desses documentos que, outro giro, devem ser regularmente revisados. Neste sentido, os atores sociais envolvidos com o fenômeno da judicialização não podem ignorar o lugar e a importância dessa normativa infralegal, sob pena de inviabilizar a gestão do Sistema Único de Saúde.

\section{CONSIDERAÇÕES FINAIS}

Na apresentação do livro Direito Sanitário: Saúde e Direito, um Diálogo Possível, Tammy Angelina Mendonça Claret Monteiro destaca dois méritos da publicação: o panorama conceitual que emerge do conjunto dos textos e o preenchimento da lacuna sobre os temas de Direito Sanitário em Minas Gerais. Esses são, realmente, dois dos maiores méritos deste livro, mas não os únicos. A densidade das discussões e a riqueza que se encontra nesse debate, fazem desse, um livro denso e importante para os estudos em Direito Sanitário. 
As abordagens diversas e não necessariamente concordantes e o caráter interdisciplinar do debate levantado enriquecem a discussão e dão uma pluralidade singular ao conjunto da obra. A riqueza da experiência em formação em Direito Sanitário, resultante da parceria entre a ESP-MG e o CEPEDISA, e a profundidade dos artigos sobre temas gerais do Direito Sanitário são também pontos marcantes do livro.

Outro o mérito que merece destaque é o de desenhar um quadro detalhado da judicialização em Minas Gerais, contribuindo, como já dito, para a discussão em âmbito nacional, sobre a questão. Os artigos deste último bloco parecem compor um mosaico, representando as diversas faces do mesmo fenômeno para apresentar um quadro integral, que atende à complexidade inerente ao tema: (i) o perfil das decisões judiciais em saúde pública (ii) a evolução do entendimento do Poder Judiciário nessas demandas; e (iii) a evolução dessas demandas, especificamente, na Microrregião de Saúde de Betim; (iv) um perfil das demandas por medicamentos; ( $v$ ) a demanda por um medicamento específico que se destaca daqueles outros; (vi) a judicialização e os medicamentos não registrados na ANVISA; e (vii) o tratamento experimental financiado pelas demandas judiciais; e (viii) um estudo a partir de um caso concreto, rico tanto pela análise, como pelas peculiaridades do caso concreto.

De uma maneira geral, o livro cumpre com excelência seu desiderato, contribuindo e aprofundando o debate sobre os temas centrais do Direito Sanitário.

\section{REFERÊNCIAS BIBLIOGRÁFICAS}

BARROSO, Luís Roberto. Da falta de efetividade à judicialização excessiva: direito à saúde, fornecimento gratuito de medicamentos e parâmetros para atuação judicial. Disponível em: <www.Irbarroso.com.br/pt>. Acesso em 01 mar.2011.

FLEURY, Sônia. A reforma sanitária: processo histórico. In: Banco Internacional de Desenvolvimento (BID). A construção da reforma sanitária no Brasil e os desafios para os gestores. 2. ed. INDES, 2009.

MARQUES, Silvia Badim. Judicialização do direito à saúde. Revista de Direito Sanitário, São Paulo, v. 9, n. 2, p. 65-72, out 2008,

MARQUES, Silvia Badim; DALLARI, Sueli Gandolfi. Garantia do direito social à assistência farmacêutica no Estado de São Paulo. Revista de Saúde Pública, São Paulo, V. 41, n. 1, p. 102-107, 2007.

VIAL, Sandra Regina Martini. Direito fraterno na sociedade cosmopolita. Revista do Instituto de Pesquisas e Estudos, Bauru, v. 40, n. 46, p. 119-134, jul./dez. 2006. 